\title{
POLÍTICAS CONTEMPORÂNEAS: FIM DO DIREITO À SAÚDE? *
}

\author{
Eduardo Jorge Alves Sobrinho**
}

RESUMO: O autor apresenta o tema em duas partes distintas: na primeira, analisa o período pós Constituinte e da reforma do Estado no Brasil no âmbito do Sistema Único de Saúde e numa segunda analisa as políticas contemporâneas e o desiderato constitucional do direito à saúde no Brasil. Apresenta inicialmente um quadro com valores do IDH da ONU, transportando o conceito para uma comparação livre com os estados brasileiros mostrando a desigualdade da distribuição de recursos e a qualidade de vida nos diferentes estados do Brasil. Em seguida apresenta o SUS como política de escopo nacional em um contexto de reforma institucional, destacando e ilustrando com diversos dados cinco pontos básicos dessa reforma: a universalização do direito à saúde, a descentralização unificada, a democratização da gestão, a integralidade da assistência, e a execução mista do sistema. Aborda ainda a questão do financiamento dessa política universalizante e integral no contexto do orçamento público brasileiro e a recente reforma constitucional relativa ao tema. Destaca as orientações programáticas em direção ao auto-cuidado; a importância de se aliar os avanços políticos a novos mecanismos de gerência com vistas ao papel regulador nos diferentes níveis de gestão do sistema; a necessidade dos pactos sociais como processo de implantação de políticas em um país das dimensões e da complexidade do Brasil. Conclui o autor com uma proposta de reforma organizacional que dê sustentação à ampla política de seguridade social no país considerando as áreas da saúde, da previdência e da assistência social.

PALAVRAS-ChaVe: cidadania, política de saúde, Sistema Único de Saúde, Estado

\footnotetext{
* Apresentado na Mesa Redonda Políticas Contemporâneas: fim do direito à saúde?, em 01/10/01, VII Congresso Paulista de Saúde Pública.

** Médico Sanitarista e Secretario Municipal de Saúde de São Paulo.
} 
Eu agradeço o convite dos organizadores do Congresso, e farei a minha intervenção em duas partes: na primeira apresento uma série de transparências sobre esse período pós Constituinte e da reforma do Estado, que é o Sistema Único de Saúde, e numa segunda parte eu apresento algumas idéias e sugestões sobre como enfrentar a pergunta: fim do direito à saúde?!

Para não esquecer que nós estamos no Brasil, vamos usar um mapa que mostra a aplicação do IDH no Brasil. IDH, vocês sabem, é o Índice de Desenvolvimento Humano que a ONU desenvolveu para fazer frente à visão dos economistas, que fazem tudo em PIB per capita. A aplicação do IDH no Brasil, de uns quatro anos atrás, se não me engano mostra com muita clareza como o nosso país é dividido, não em dois, talvez em três Brasis. Podemos ver a aplicação do IDH, estado por estado: o Rio Grande do Sul, como o melhor, e a Paraíba, a minha Paraíba, em último lugar; São Paulo está em terceiro. Se os nossos estados federados fossem países e se filiassem à $\mathrm{ONU}$, como é que eles se classificariam nesse "rank" de IDH feito pela ONU há uns três, quatro anos atrás? O primeiro estado brasileiro, que é o Rio Grande do Sul, ficaria ali no quadragésimo lugar junto da República Tcheca, Brunei, Venezuela e um pouco abaixo do Chile. A Paraíba estaria em último lugar, ficaria entre os cento e oitenta e tantos países filiados à ONU, em último lugar na classificação do IDH. Isso é uma coisa de uma brutalidade e de uma expressividade total, estar em último lugar! Alagoas, Piauí, estão ali abaixo de Camarões; o Ceará está entre Papuá-Nova Guiné e Camarões, etc; Maranhão está entre Suazilândia e as Ilhas Salomão; essa é uma questão muito importante, a gente não pode esquecer de quê País se está falando, de quê características desse País, gigantesco, que tem tantas potencialidades mas que é tão desigual. É num País desse que nós estamos trabalhando, num País campeão de desigualdades.

Nesse sentido, a reforma do Estado, do SUS, traçou um rumo que tem, do meu ponto de vista, cinco orientações básicas: a universalização do direito, a descentralização unificada, a democratização da gestão, a integralidade da assistência, e a execução mista. Com essas cinco grandes orientações, nós começamos a reforma, uma reforma de um sistema mais do que centenário. Houve a regulamentação em 1990, mas a Lei decisiva foi a de 1993 quando finalmente Brasília concordou com a descentralização do gigante que era o INAMPS. Teve também o interregno 89/90 do governo que sucedeu a Constituição, cuja orientação foi francamente anti-universalização, anti-SUS. A partir de 93 essa reforma começou a "pegar ritmo", com o Ministro Jamil Hadad, do PSB do Rio de Janeiro. 
Os números são muito expressivos em relação ao primeiro elemento da reforma - a universalização, nós, SUS, somos hoje $100 \%$ responsáveis pelo atendimento de 120 milhões de brasileiros, dos quais 60 milhões eram, antes da Constituição democrática e antes da reforma do SUS, indigentes sanitários; dependiam de uma Santa Casa, onde ela existisse, ou de uma eventual estrutura municipal estatal, rara, também onde existisse. Houve portanto bruscamente uma inclusão na cidadania sanitária, de 60 milhões de pessoas, o que é um resultado expressivo, uma conquista democrática inesquecível, que o povo brasileiro - com a Constituição democrática de 89 - inscreveu de forma a tornar essa proposta um santuário da democracia. Isso traz muitas dificuldades, você não incorpora 60 milhões de pessoas de uma vez sem causar transtornos e dificuldades no Sistema. A universalização foi um avanço, um salto, apesar da classe média e dos trabalhadores especializados terem "fugido" dessa vinda de 60 milhões de excluídos para dentro do Sistema. Mas não há dúvida que a universalização avançou no Brasil. Se você comparar os dados, a cada ano, do que o Sistema Único de Saúde produz em termos de procedimentos: 1 bilhão de procedimentos, 350 milhões de consultas médicas, 50 milhões de vacinas, praticamente $100 \%$ da hemodiálise. Pode se perguntar hoje: a expansão da universalização foi mais na atenção básica, na vacinação, onde erradicamos a poliomielite, vamos erradicar o sarampo nos próximos anos, antes inclusive, do que alguns países europeus? Não, a universalização não avançou só na atenção chamada básica, ela avançou também na outra ponta do Sistema, na ponta da alta complexidade. Hoje o Brasil em números absolutos de transplantes, só está perdendo para os Estados Unidos; em números relativos, em relação à população nacional, o Brasil é o quinto ou sexto País e se você introduzir a variante do PIB per capita nesse cálculo, o Brasil vai pra frente dos Estados Unidos em capacidade de transplante. É um procedimento caro, que hoje está organizado pelo Sistema Único de Saúde, é claro, com uma fila, mas uma fila democrática. Portanto, a universalização, tanto na base quanto na cúpula do Sistema "pegou ritmo", quem examina os dados da produção do Sistema Único de Saúde é obrigado a reconhecer a grandiosidade dessa tarefa nesses cinco, sete anos principalmente, porque a minha referência é sempre de 93 pra cá.

O segundo princípio, que é o da descentralização e mostra que praticamente $97 \%$ dos municípios, em 1999 já tinham algum tipo de integração ao Sistema. Hoje já está bem mais avançado, chegando a 99\%, e agora, com a entrada de São Paulo, vai a 99,9\%. Nesse ponto, a descentralização unificada com o vetor da municipalização, muito radical no começo, exige uma série de ponderações. Por exemplo, a municipalização hoje passa pela necessidade de um tempero que é a regionalização, para evitar que haja uma espécie de instituição de autarquias municipais separando e fragmentando o Sistema. Mas foi importante 
acreditar no vetor municipalização. Em Brasília ninguém acreditava, a burocracia brasiliense não acreditava nisso, então foi muito importante você radicalizar no vetor municipalização, e agora temperar com o vetor regionalização. Existe uma heterogeneidade muito grande de administração, de capacidade de gestão, existe uma indefinição muito dramática que gera problemas até psicológicos, que é a indefinição do papel do governo estadual, que era uma instância muito forte na fase pré Constituição e que hoje, com a municipalização, passa por um processo ainda de clarear qual é o seu papel articulador.

Como eu disse, há uma heterogeneidade muito grande na capacidade de gestão. Mas quem conhece o Brasil e sabe que, por exemplo, na Paraíba, dos 140, 150 municípios, só quatro ou cinco tinham secretarias municipais de saúde em 1990 e hoje, se você for lá, os 150 municípios têm Secretaria Municipal de Saúde. Têm uma autoridade sanitária ao alcance da mão de uma pessoa lá em Bonito de Santa Fé, lá em Caaporã, lá em Catolé do Rocha. Isso é uma coisa fantástica, porque muitos desses municípios eram municípios virtuais, estavam lá para receber o Fundo de Participação do município, pagar Vereador, ter Fórum e pagar Prefeito; com a municipalização, passaram a ter uma tarefa, uma política pública pela qual estão responsáveis. E não é qualquer política pública! É uma política pública altamente complexa que é a saúde, e hoje recebem esses municípios dinheiro independente de pedir a benção ao coronel do Estado. É o que permite, por exemplo, Vitória da Conquista, em plena Bahia - que é um reduto do coronelismo, como todo mundo sabe, ainda remanescente no Brasil - ter possibilidade de receber recursos e implantar um sistema no coração do sertão, da qualidade que tem o Sistema de Saúde em Vitória da Conquista. Então, com todas as dificuldades, dessa heterogeneidade de capacidade de gestão, dessa indefinição do aparelho, principalmente no âmbito da instância estatal, é preciso registrar que esse segundo ponto do SUS avançou bastante.

O terceiro ponto, a questão da democratização. Esta transparência mostra a distribuição dos médicos brasileiros em 1995, ainda estávamos em 200 mil, nós já somos 270 mil médicos, e a distribuição estado por estado, mostrando a incrível concentração desses médicos na região Sudeste. E pior, quando você chega num estado do Norte e Nordeste, que tem poucos profissionais, eles estão quase todos na Capital. Veja a situação, por exemplo, de Sergipe, 92\% estão em Aracaju; no Ceará, 82\% estão em Fortaleza; em Alagoas, $88 \%$ estavam em Maceió e assim por diante. O IBGE no ano passado comparou - Brasil sanitário de $92 \mathrm{com} 99$, é o primeiro trabalho do IBGE comparativo da distribuição de postos de trabalho médicos antes e depois do processo de implantação do SUS no Brasil. A distribuição em 1992, início do processo, apresentava grande concentração no Rio 
de Janeiro, em Brasília, e em São Paulo, e um grande vazio pegando toda a região do Centro Oeste, Nordeste e Norte. Em 1999, segundo o IBGE houve uma evolução. Os postos de trabalho médicos entraram Brasil adentro, já resultado desse processo de descentralização unificada e do vetor municipalização. Essa é uma diferença realmente importante em termos de distribuição.

Outro aspecto da questão da democratização é a meta de inscrição dos conselheiros municipais e estaduais num curso de formação que o Ministério da Saúde, com financiamento internacional e articulado pela FIOCRUZ, pretende oferecer para $50 \%$ dos conselheiros. $O$ dado importante é esse aqui, são 43 mil pessoas, 43 mil conselheiros municipais, o que significa que nós somos hoje no Brasil cerca de 100 mil conselheiros municipais. Toda vez que o Ministério da Saúde ou o Conselho Nacional de Saúde convocam uma reunião de conselheiros municipais em Brasília eles reúnem um auditório desse, para 700 pessoas, vêm 1500; propõem um auditório de 1500, vêm 2000; propõem um auditório de 2000, vêm 3000 , mostrando que existe essa participação, esse desejo de participar. Responderam a algo que em Brasília, quando se discutia no Congresso Nacional, muitas vezes se duvidava se isso aconteceria, porque alguns políticos de matiz mais conservadora diziam: "Na minha cidade quem manda sou eu, não tem essa história não. Vocês estão pensando que estão na Suécia? Nós não estamos na Suécia". Mas na verdade existem conselhos municipais, heterogêneos não há dúvida, mas eles estão implantados em praticamente 5 mil municípios; são donas de casa, operários, comerciantes, camponeses, funcionários públicos, que se reúnem com a autoridade sanitária para ter acesso às informações e influenciar, criticar o trabalho de uma política pública. Isso não existe, nessa dimensão, na história do Brasil, um movimento desse tamanho, não existe com essa institucionalidade, com essa estabilidade, com essa reserva e retaguarda legal que o Sistema Único de Saúde permite a esse tipo de participação social.

O quarto item, é a questão da integralidade que vai da atenção básica aos procedimentos mais complexos. Em relação à Saúde da Família saímos em 1994 praticamente do zero, e em 2001 as metas estão sendo cumpridas, mostrando como o Programa de Saúde da Família, essa estratégia de atenção básica se enraizou. A velocidade de abraçar o território brasileiro foi fantástica. Isso aí é a velocidade vertiginosa que o Sistema tem imprimido a esse Programa.

Indo para o outro lado da ponta do Sistema, há a questão do transplante, que eu falei pra vocês. Os dados da Associação Brasileira de Transplante de Órgãos mostram 
outra ponta da expansão do Sistema. Em 1995, nós estávamos realizando 1800 transplantes, nós realizamos em 2000, 2907 transplantes de rim. O Hospital do Rim e da Hipertensão, que é um hospital anexo ao Hospital São Paulo, realizou no ano de 2000, praticamente um transplante por dia, foi o hospital que realizou mais transplantes na história de toda a assistência à saúde no mundo. Veja outro dado impressionante, nós fizemos em 1995, 463 transplantes de córnea, e em 2000, 3384. Estes transplantes são realizados quase que $100 \%$ pelo Sistema Único de Saúde.

O quinto item é a questão da execução mista, há uma evolução positiva, principalmente no atendimento ambulatorial, onde a rede pública cresceu e hoje é responsável por mais de $70 \%$ do atendimento no Brasil inteiro. No atendimento hospitalar continua havendo uma hegemonia expressiva do setor privado, e o setor público não ultrapassa os $33 \%$, entretanto na área ambulatorial há um crescimento real dos serviços públicos municipais e os estaduais e federais municipalizados são, hoje, responsáveis por mais de $70 \%$ desses atendimentos no Brasil inteiro. É claro que existem problemas como a renúncia fiscal, escandalosa, a favor do sistema privado. Existe uma regulação muito incipiente e tateante do setor privado, mas esse casamento e essa soma, esse aproveitamento do investimento público e privado seguindo os outros quatro princípios (universalização, integração, democratização, descentralização) mostrou-se altamente produtivo comprovando uma posição correta do Congresso Nacional ao estabelecer essa convivência na execução, tanto do setor público quanto do setor privado, filantrópico e lucrativo, que devem é claro, seguir os princípios do Sistema Único de Saúde.

Finalmente, comentados esses cinco itens, cinco rumos, chegamos no problema do financiamento, que é um problema crucial. Apresento dados do Conselho Nacional de Saúde e do Ministério da Saúde. Os gastos federais são cerca de 60 e poucos por cento do Sistema, por isso que eu estou dando mais ênfase a eles; os municipais são cerca de $23 \%$ e os estaduais cerca de $17 \%$. Houve um pulo em valores nominais de 1996 a 1997, devido a introdução da CPMF. Se você passa para valores médios do IGP, se vê que houve realmente um salto de 96 pra 97, houve uma recuperação e uma estabilização. Pelos valores do IPC Saúde, a diferença é maior ainda, porque a inflação da Saúde é uma inflação maior do que a inflação média normal. Do ponto de vista per capita, nominal, nós crescemos, mas do ponto de vista médio nós estamos inferiores. Na verdade, a CPMF foi um instrumento que possibilitou um fôlego diferente e adicional para o Ministério da Saúde, porque a política continua sendo de contenção de gastos na área social, na área da reforma agrária, na área militar, na área do Itamarati, em todas elas. Esse dado é muito interessante pois mostra que 
houve um crescimento expressivo dos gastos com atenção básica mesmo tendo em conta a inflação da saúde. $\mathrm{Na}$ área hospitalar, isso não aconteceu, houve até uma regressão, uma diminuição. Esse dado é um dado muito importante porque é uma estimativa do impacto da vinculação da Emenda Constitucional de recursos para a saúde. Isso mostra como a Emenda Constitucional é importante para estabilizar e dar um discreto fôlego numa conjuntura de arroxo orçamentário. Nós sairíamos de um gasto de cerca de 31 bilhões pra um gasto de cerca de 44 bilhões, há uma expansão inclusive em termos de PIB de $3 \%$ para $3,8 \%$. 0 Brasil se classificaria, em termos da sua renda per capita e dos gastos com saúde comparado com os países da Comunidade Européia, junto com a Turquia. Isso mostra o quanto falta de recurso, mas mostra também o quanto o Brasil já andou nesse esforço de reforma de Estado que é o Sistema Único de Saúde.

Eu passo agora à segunda parte, apresentando algumas idéias quanto à pergunta colocada aqui pela Mesa - fim do direito à saúde?! - para que do meu ponto de vista, essa ameaça, essa indefinição possa evoluir para um final feliz.

Uma primeira questão: em relação à separação entre a política e a gerência, eu não vejo o menor sentido nessa separação, elas estão intimamente associadas, você não pode avançar nos direitos políticos, na participação política, se o Sistema Único de Saúde não aperfeiçoar, não incorporar inclusive mecanismos mais modernos e mais fortes de regulação e de gerência. Não vejo então como separar uma necessidade de uma evolução, tanto da política do direito do cidadão quanto da exigência de novos mecanismos mais eficientes de gerência do Sistema Único de Saúde.

A segunda questão importante é o tema do auto-cuidado, ou seja, o cidadão, a cidadã, cada vez mais se apropriar dos conceitos científicos e ele próprio cuidar da sua saúde, da sua família, eu acho que tem um efeito emancipatório muito importante. Eu dou uma atenção e uma importância grande a essa questão da educação na saúde, que em nosso Sistema Único de Saúde, praticamente não andou, estão preocupados com Pronto Socorro, com PSF, e a questão de educação em saúde praticamente é um terreno virgem e está ligado ao tema do auto-cuidado como fator de emancipação do cidadão e da cidadã. Eu tenho que cuidar de mim mesmo, em primeiro lugar, tenho que saber conversar e discutir com o médico, com a enfermeira, o quê que é melhor pra mim.

O terceiro tema é o tema da universalização, tema muito complexo, atacado o tempo todo pelos defensores da segmentação. Temos que reafirmar a possibilidade da 
universalização, e aí eu vejo um tema até legislativo, que é a questão da isenção do subsídio para os trabalhadores especializados e para a classe média e para a burguesia, que hoje no Brasil se dá. Levando em conta aquele mapa inicial que a gente viu, dar 2 bilhões de reais de subsídio para planos de seguro privado, é um absurdo, faz parte da pauta lutar pela universalização suspender esse subsídio e vinculá-lo à melhoria de qualidade do Sistema Único de Saúde. Tem que se articular uma priorização, no meu ponto de vista, no Sistema Único de Saúde na qualidade da atenção básica, por um lado, e na outra ponta, aqueles chamados riscos catastróficos ter uma atenção especial. Isso significa não ter medo de priorizar, não quer dizer que nós vamos segmentar e focalizar de forma definitiva, mas às vezes você tem que focalizar pra caminhar na direção da universalidade. Esse é o risco de governar, de fazer as escolhas orçamentárias, sempre no sentido, insisto, da universalidade e não de cristalizar a desigualdade; portanto, é um movimento de pinça, que vem da qualidade da atenção básica e com o atendimento mais complexo, fechando e ocupando espaços, disputando espaço com a chamada Medicina Suplementar.

O quarto aspecto que eu quero colocar é a necessidade de pactos sociais no Brasil. Um país continental e complexo como o nosso, se não conseguir estabelecer entre as várias forças políticas, alguns pactos mínimos na área de saúde, na área da educação, na área de previdência social, essas políticas continuarão de forma muito errática, se beneficiando pouco dessa virtude da democracia que é você poder mudar de governo de quatro em quatro anos. Isso implica que os partidos, sejam eles conservadores ou socialistas, e a outras forças da sociedade civil, tenham capacidade e estabeleçam pactos sociais mínimos, tarefas que tenham continuidade quando se muda de governo. A área da saúde é aonde essa possibilidade está mais avançada, talvez uma das que possa fazê-lo a curto prazo.

A quinta questão é a da seguridade social. Eu sou a favor de uma pauta também legislativa, que é retomar a discussão do Ministério da Seguridade Social, que eu chamo de Ministério da Defesa Popular. Tem o Ministério da Defesa propriamente dito, então nós precisamos de um Ministério da Defesa Popular, porque aí haveriam três grandes áreas ministeriais em Brasília: a Economia, que é uma espécie de Primeiro Ministro informal; o Exército a Aeronáutica e a Marinha, reunidos no Ministério da Defesa porque têm a força das armas, e o nosso Ministério da Defesa Popular, reunindo Saúde, Previdência e Assistência Social, com orçamento poderoso, capaz, aí sim, de se ombrear nas discussões que existem no Palácio do Planalto, quando se vai discutir política e orçamento. Portanto, eu continuo defendendo o Ministério da Seguridade Social, a extinção do Ministério da Previdência e da 
Saúde, e reuni-los num Ministério unificado, com orçamento da Seguridade Social também unificado. Isso implica numa outra pauta, ainda nessa questão da seguridade social, que é fazer a reforma previdenciária; a reforma previdenciária não foi feita, a reforma previdenciária no sentido da universalização do direito não foi feita, foi feito um remendo pela metade recentemente, mas a universalização para tornar compatível com o tipo de universalização que se defende com a saúde tem que ir fundo na área da Previdência. Não é possível o Brasil ter essa miríade de sistemas de previdências porque isso faz parte do equilíbrio orçamentário e daí é que vai sair o dinheiro. Também, não é só atacar a mudança da relação com os bancos, com a dívida, etc. A questão da Previdência é uma questão importantíssima para a estabilidade do orçamento nacional e particularmente do orçamento da Seguridade Social, portanto é preciso fazer uma reforma da Previdência de verdade, direitos iguais para todos.

E, terminando ... sobre a associação de globalização com o mercado. Hoje a globalização é hegemonizada pelo mercado. Isso não é uma fatalidade; eu defendo a globalização hegemonizada pela política. Isso significa você ter Estado, ter uma federação democrática de Nações, em nível mundial, que governe o mundo; e aí articular a saúde nesse perfil, porque muita coisa hoje só é possível fazer em nível mundial. Isso vale para a ecologia, vale para a segurança e vale para a saúde. Imaginem, por exemplo, se o Paraguai pode ter política de medicamento, não existe, não existe possibilidade, então eu não faço essa separação, essa identificação mecânica e fatalista, globalização igual a mercado. Globalização pode ser igual também à política, à democracia, e articulação no nível planetário das políticas públicas, isso sim que é um futuro positivo, uma pauta positiva em relação a esse tema da globalização e da saúde. 


\title{
CONTEMPORARY POLICIES: IS IT THE END OF RIGHT TO HEALTH?
}

\begin{abstract}
The author presents the subject in two parts: in the first part, he analyses the post-National Constituent Assembly period and the reform of the State in Brazil regarding the Unified Health System (SUS); in the second part, he analyzes the contemporary policies and the constitutional desideratum of right to health in Brazil. A chart with the Human Development Index (UN) values is initially presented, carrying the concept to a free comparison with the Brazilian States and showing inequality between distribution of resources and quality of life in different states. Afterwards, SUS is presented as a national policy in a context of institutional reform, highlighting and illustrating five basic issues of the reform with several data: universalization of the right to health, unified decentralization, democratization of management, healthcare integrality, and combined management of the system. The paper also addresses the issue of financing this universalizing and integral policy in the context of the Brazilian public budget and the recent constitutional reform related to the topic. It points out the program orientations towards self-care; the importance of joining political advances and new management mechanisms aiming at regulatory role at different management levels in the system; the need of social pacts as a process to implement policies in a country as large and complex as Brazil. The author concludes putting forward a proposal of an organizational reform that supports the broad social security policy in the country, taking into account health, social security and social care.
\end{abstract}

KEYWORDS: citizenship, health policy, Unified Health System, State 